\title{
Communication
}

\section{Wind Tunnel Testing of Plasma Actuator with Two Mesh Electrodes to Boundary Layer Control at High Angle of Attack ${ }^{\dagger}$}

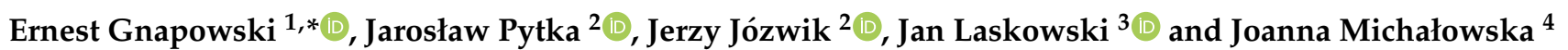 \\ 1 Faculty of Technical Sciences, University College of Enterprise and Administration, 20-150 Lublin, Poland \\ 2 Faculty of Mechanical Engineering, Lublin University of Technology, 20-618 Lublin, Poland; \\ j.pytka@pollub.pl (J.P.); j.jozwik@pollub.pl (J.J.) \\ 3 Faculty of Management, Lublin University of Technology, 20-618 Lublin, Poland; jlasko@wp.pl \\ 4 The Institute of Technical Sciences and Aviation, The State School of Higher Education, 22-100 Chełm, Poland; \\ jmichalowska@pwsz.chelm.pl \\ * Correspondence: egnapowski@gmail.com \\ + This paper is an extended version of our paper published in: Gnapowski, E.; Pytka, J.; Józwik, J.; \\ Michałowska, J. Wind Tunnel Testing of Mesh Electrodes Plasma Actuator. In Proceedings of the 7th IEEE \\ Workshop on Metrology for AeroSpace, Pisa, Italy, 22-24 June 2020.
}

Citation: Gnapowski, E.; Pytka, J.; Józwik, J.; Laskowski, J.;

Michałowska, J. Wind Tunnel Testing of Plasma Actuator with Two Mesh Electrodes to Boundary Layer Control at High Angle of Attack. Sensors 2021, 21, 363. https://doi.org/10.3390/ s21020363

Received: 3 December 2020

Accepted: 4 January 2021

Published: 7 January 2021

Publisher's Note: MDPI stays neutral with regard to jurisdictional clai$\mathrm{ms}$ in published maps and institutional affiliations.

Copyright: $\odot 2021$ by the authors. Licensee MDPI, Basel, Switzerland. This article is an open access article distributed under the terms and conditions of the Creative Commons Attribution (CC BY) license (https:// creativecommons.org/licenses/by/ $4.0 /)$.

\begin{abstract}
The manuscript presents experimental research carried out on the wing model with the SD 7003 profile. A plasma actuator with DBD (Dielectric Barrier Discharge) discharges was placed on the wing surface to control boundary layer. The experimental tests were carried out in the AeroLab wind tunnel where the forces acting on the wing during the tests were measured. The conducted experimental research concerns the analysis of the phenomena that take place on the surface of the wing with the DBD plasma actuator turned off and on. The plasma actuator used during the experimental tests has a different structure compared to the classic plasma actuator. The commonly tested plasma actuator uses solid/impermeable electrodes, while in the research, the plasma actuator uses a new type of electrodes, two mesh electrodes separated by an impermeable Kapton dielectric. The experimental research was carried out for the angle of attack $\alpha=15^{\circ}$ and several air velocities $V=5-15 \mathrm{~m} / \mathrm{s}$ with a step of $5 \mathrm{~m} / \mathrm{s}$ for the Reynolds number $\mathrm{Re}=87,500-262,500$. The critical angle of attack at which the SD 7003 profile has the maximum lift coefficient is about $11^{\circ}$; during the experimental research, the angle was $15^{\circ}$. Despite the high angle of attack, it was possible to increase the lift coefficient. The use of a plasma actuator with two mesh electrodes allowed to increase the lift by $5 \%$, even at a high angle of attack. During experimental research used high voltage power supply for powering the DBD plasma actuator in the voltage range from 7.5 to $15 \mathrm{kV}$.
\end{abstract}

Keywords: plasma actuator; flow control; wing airfoil; wind tunnel; mesh electrodes; DBD

\section{Introduction}

Guaranteeing a high level of aircraft safety requires many experimental tests of the aircraft's components, including: landing gear [1-4], wings [5] and other components [6]. The manuscript presents and describes selected designs of DBD (Dielectric Barrier Discharge) plasma actuators, allowing us to increase flight safety by increasing the lift force. Plasma actuators DBD allow us to control the air flow in the boundary layer of the wing. It is a new solution for boundary layer control [7]. The DBD system does not have any moving parts such as rods, valves, diaphragms, cylinders or gears to activate it, thus creating no design problems that complicate the aircraft structure. One of the main mechanisms influencing the flow exerted by the DBD plasma actuator is the generation of "ion wind" $[8,9]$. As a consequence of flexible collisions between migrating charged particles and inert gas particles, they increase their energy, causing an "electric wind" that occurs in close proximity to the profile surface $[10,11]$. The construction of a plasma actuator is quite simple. It consists of two flat electrodes (the most commonly used metal/copper strips) 
that are separated by a dielectric. The dielectric prevents spark discharge that causes local increase in temperature. The first electrode is completely covered with a dielectric; the second electrode is directly exposed to the flowing air. Research by other scientists mainly focuses on changing the shape of solid copper electrodes into sawtooth, oval, rectangular and wave [12-14]. Changing the shape of the exposed electrode is aimed at increasing the discharge area $[15,16]$. These changes create a stronger "ion wind" affecting the air circulation in the boundary layer. The most frequently used frequency during experimental research is from several hundred $\mathrm{Hz}$ to several $\mathrm{kHz}$ [17-20]. The voltage range used during the experimental tests depends on the dielectric [21,22] used and ranges from a few $\mathrm{kV}$ to several dozen $\mathrm{kV}$. The manuscript presents experimental studies of a plasma actuator with a new type of electrodes. Two mesh electrodes were used in the presented studies. The use of mesh electrodes in a plasma actuator is a new design solution. The presented tunnel tests of a plasma actuator with two mesh electrodes are a new solution, not described in the literature by other researchers. The most commonly used in experimental research are solid copper electrodes impermeable to air, [23-29]. In the presented experimental studies, the grounded electrode fully covered with a dielectric is much larger, it covers about $70 \%$ of the upper surface of the wing. The main purpose of the wind tunnel tests carried out to confirm the effectiveness of the new type of plasma actuator with two electrodes for controlling the boundary layer. The research was carried out for the wing model with the SD 7003 profile (made personally by the author of the manuscript) for an angle of attack of $15^{\circ}$; for such a high angle of attack, the profile loses lift under normal conditions. The critical angle of attack at which the SD 7003 profile has the maximum lift coefficient is about $11^{\circ}$.

\section{Materials and Methods}

Experimental research was carried out with the wing model with the SD 7003 profile, $250 \mathrm{~mm}$ wide and $250 \mathrm{~mm}$ long. The wing model is made of fiberglass, balsa and plywood. Two mesh electrodes are placed on the upper surface of the wing as shown in Figure 1. A large, grounded mesh electrode is $200 \mathrm{~mm}$ long and $200 \mathrm{~mm}$ wide is full covered with four layers of Kapton dielectric and is attached directly to the wing surface. The use of a dielectric to prevent spark discharges and high local temperature increase [30,31].

The use of mesh electrodes for the construction of a plasma actuator resulted from the previous experimental results of the author of the manuscript. Previous experimental research with plasma reactors with DBD discharges have shown that the use of mesh electrodes allows obtaining homogeneous discharges. The research carried out with DBD systems with small dimension mesh electrodes allowed for obtaining the highest efficiency of ozone generation during experimental research with plasma reactors. For the construction of plasma actuators, systems with the highest efficiency must be used, because the use of systems with low efficiency will increase the weight of the aircraft without the expected impact on the boundary layer.

The HV electrode is $200 \mathrm{~mm}$ long and $10 \mathrm{~mm}$ wide and is placed on the dielectric surface at a distance of $15 \mathrm{~mm}$ from the leading edge. Both mesh electrodes are made of AISI 304 stainless steel, it prevents oxidation of the electrode surface by ozone generated during DBD, the mesh size of the electrodes was $0.05 \mathrm{~mm} \times 0.05 \mathrm{~mm}$. The electrodes are connected to a high voltage power system with a value of several $\mathrm{kV}$. The wing model was placed in the AeroLab wind tunnel (Aerolab LLC, Jessup, USA), which allows to control the air speed in the range of $V=4.5-65 \mathrm{~m} / \mathrm{s}$ and measure the forces acting on the wing during experimental tests. The measuring stand and the wind tunnel are shown in Figure 2. 

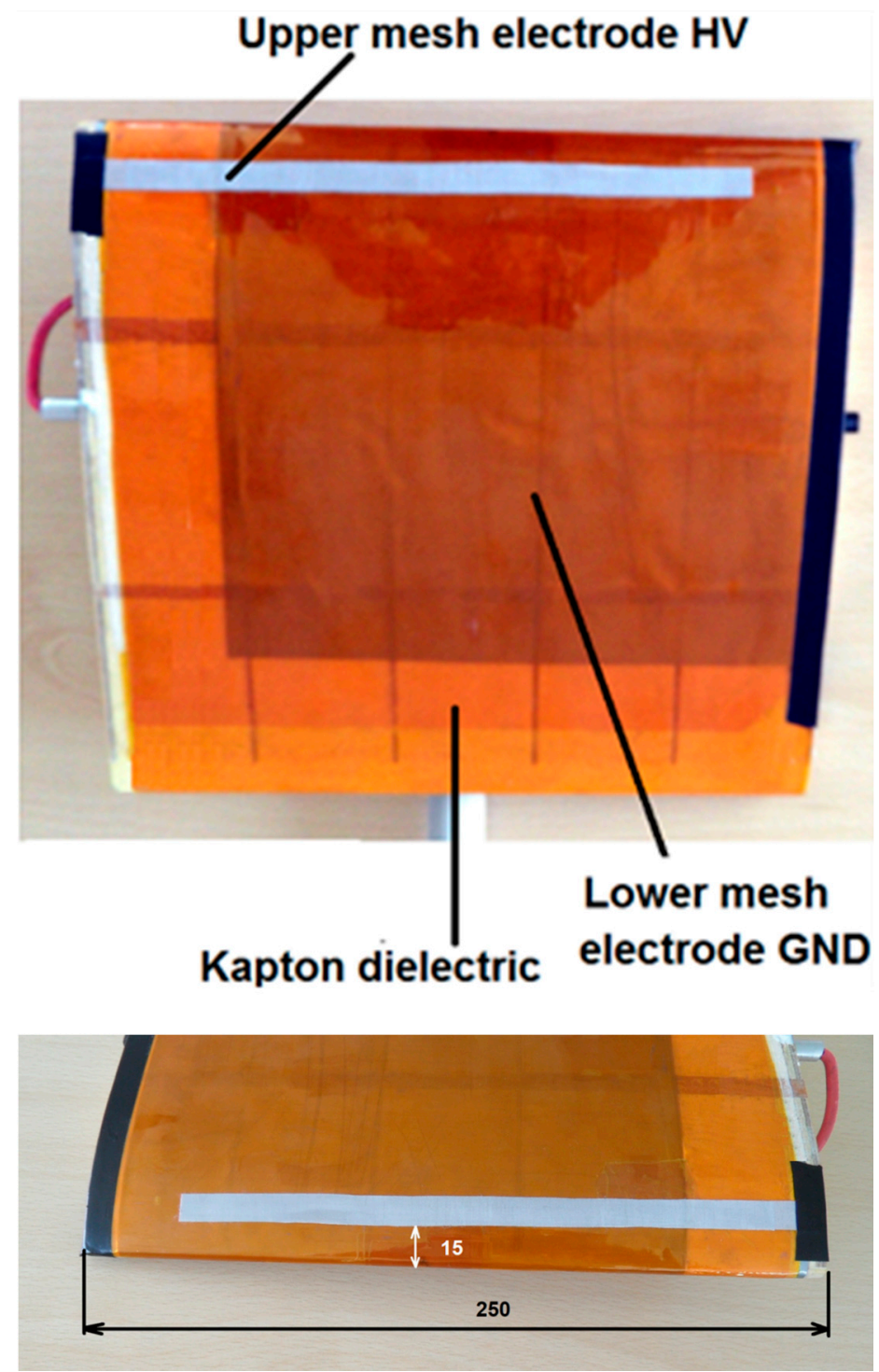

Figure 1. Wing model with the profile SD7003, with a visible plasma actuator with two mesh electrodes.

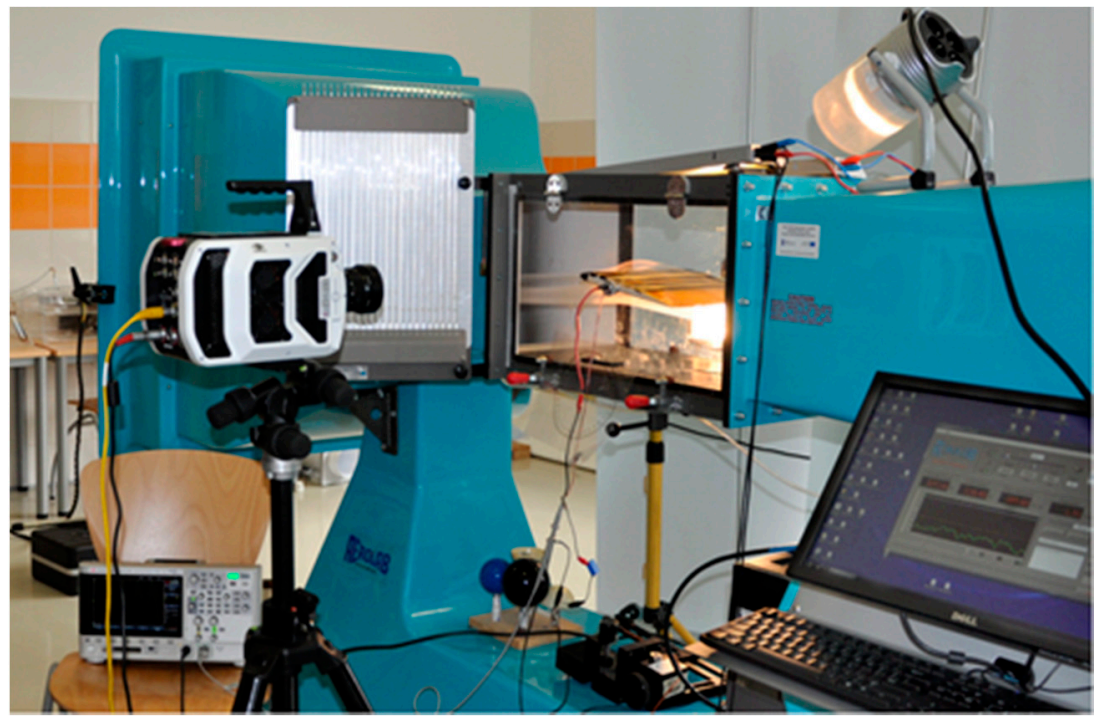

Figure 2. Measurement stand with equipment. 
A typical DBD plasma actuator system with two solid electrodes is shown in Figure 3a. Figure $3 \mathrm{~b}$ shows the setup and operation of the test system with two mesh electrodes.

a)

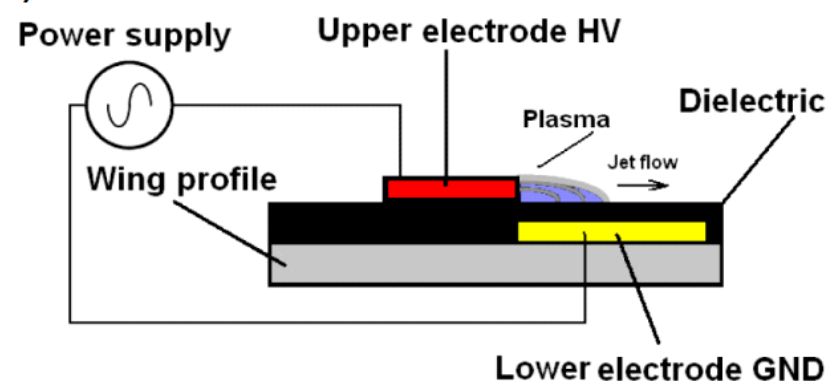

b)

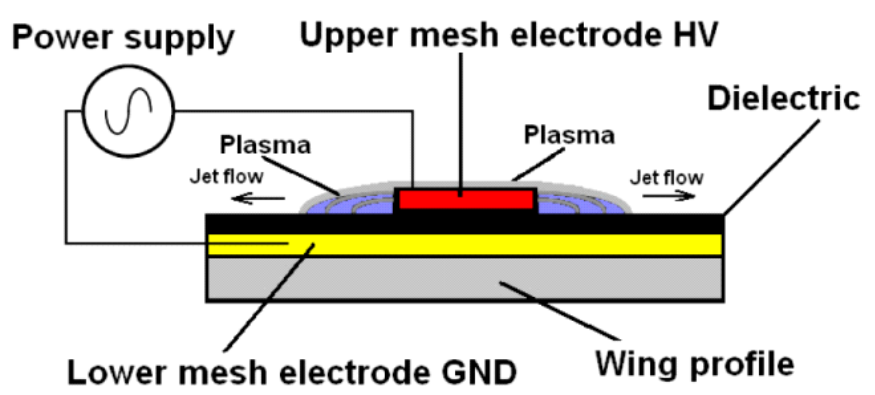

Figure 3. Construction of plasma actuators: (a) classic plasma actuator with solid electrodes with visible discharges only on one edge, (b) plasma actuator with two mesh electrodes with discharges visible on two edges and directly through the surface of the HV electrode.

Comparing the design of the plasma actuators in Figure 3 a with classic plasma actuator with solid electrodes and Figure $3 b$ with two mesh electrodes, differences in the structure and surface of the discharges can be seen. The use of mesh electrodes allows us to obtain a larger surface of discharges compared to the classic plasma actuator with solid electrodes; it is possible due to the use of an HV mesh electrode. Discharges in a plasma actuator with solid electrodes are generated at only one edge of the HV electrode. The use of mesh electrodes in the model presented in the manuscript allows for a larger area of discharges because the discharges occur at the two edges of the mesh electrode as well as directly through the surface of the HV electrode, which additionally increases the area of discharges. The entire surface of the high-voltage electrode forms one wide discharge.

Figure 4 compares the real design of the plasma actuator with solid electrodes in an asymmetric configuration Figure $4 \mathrm{a}$ and the tested plasma actuator with two mesh electrodes Figure $4 b$.

The experimental research presented in the manuscript were carried out for three air flow velocities of $V=5,10$ and $15 \mathrm{~m} / \mathrm{s}$ and an angle of attack of $15^{\circ}$. During the experimental research, the air flow velocities were changed in steps of $5 \mathrm{~m} / \mathrm{s}$.

An autotransformer and a high voltage transformer 230/10,000 V $50 \mathrm{~Hz}$ were used to power the DBD plasma actuator located on the wing surface. Lissajous figures and high voltage were recorded during the experimental tests.

The measurements were performed with the Keysight DSO X 2012A 200 MHz, 2 GS/s oscilloscope (Keysight, Santa Rosa, CA, USA), equipped with a Tektronix P6015A highvoltage probe (Tektronix, Inc, Beaverton, OR, USA) and a Tektronix P2220 1:1/10:1 current probe (Tektronix, Inc, Beaverton, OR, USA). Figure 5 shows a diagram of the measurement system with individual elements marked. The internal structure of the wing model is also shown in Figure 5, and in particular the arrangement of the individual layers of the dielectric and electrodes. A photo of the real wing model used in the experimental tests is shown in Figure 1, with a description of the individual elements. The photo of the wing 
model shows a large, grounded electrode GND full covered with a dielectric; on the surface of the dielectric there is a high-voltage HV electrode.
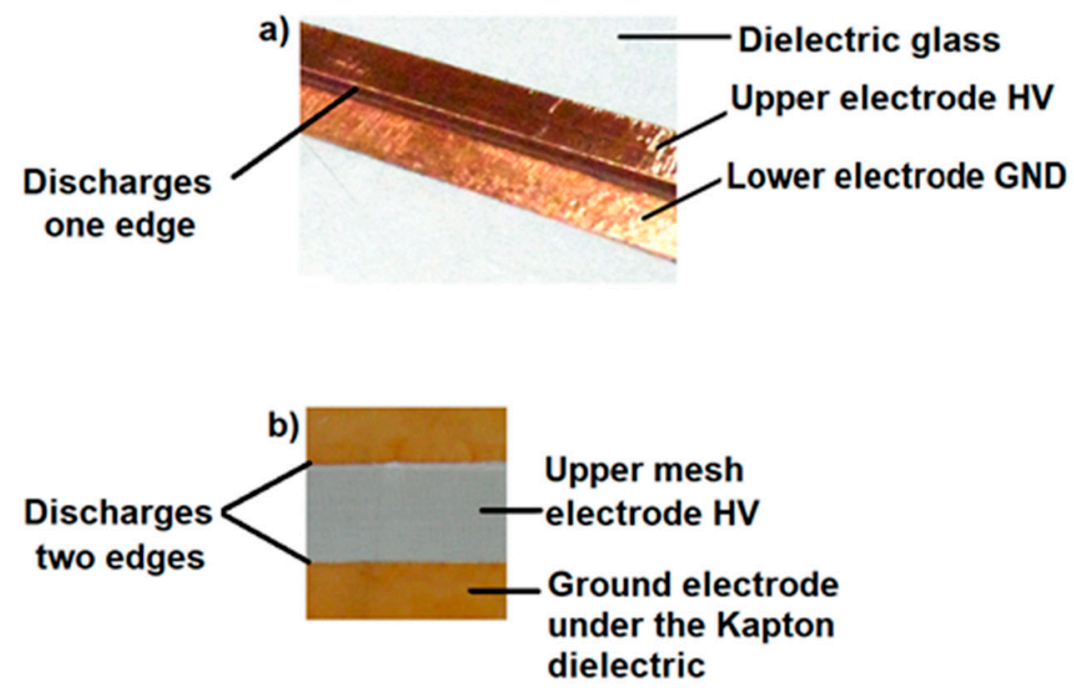

Figure 4. Comparison of the design of plasma actuators: (a) classic with solid electrodes and, (b) with two mesh electrodes.
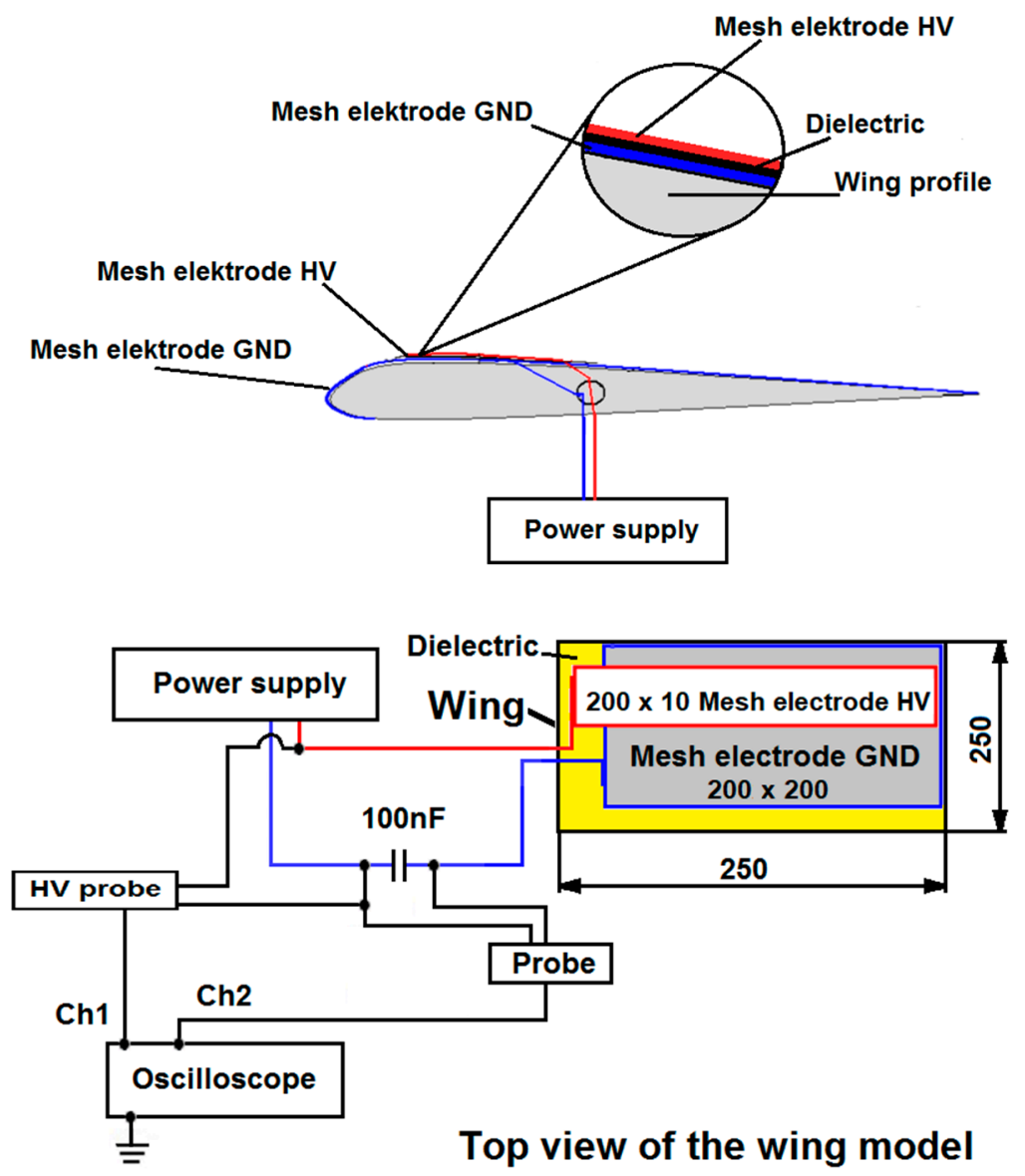

Figure 5. Measurement diagram and electrode system arranged on the wing model.

During the experimental tests in the wind tunnel, photos of the wing model for individual air flow velocities were recorded using the Phantom V2511 (Vision Research, Wayne, NJ, USA) high-speed camera. 
During the experimental research, the wing model was placed inside the AeroLab wind tunnel. The DBD plasma actuator is located on the upper surface of the wing model as shown in Figure 6. The wing model with the DBD plasma actuator was placed directly on the balancing force, which allows the registration of the forces acting on the model during experimental research. Figure 6 shows the wing model placed on the balancing force during experimental tests in the wind tunnel.

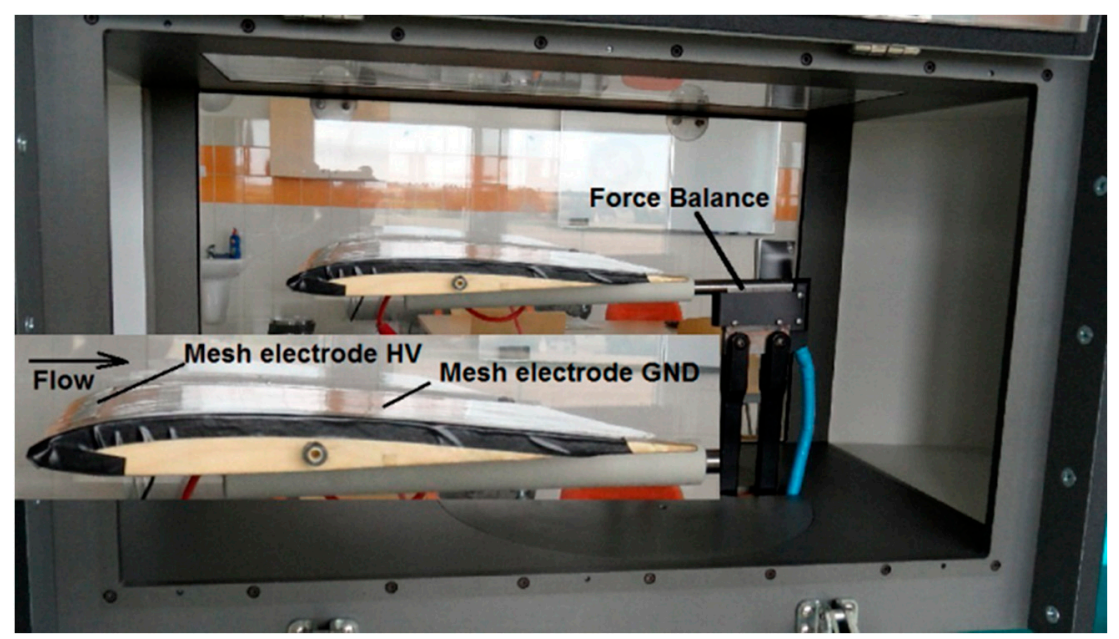

Figure 6. Wing model placed inside the wind tunnel.

During the experimental research, a smoke generator was used, which allowed the observation of changes in air flow on the wing surface and the formation of turbulence.

\section{Results}

During the experimental research, use of the oscilloscope allowed for the recording of Lissajous figures with which the power of the discharges was calculated. Figure 7 shows an exemplary Lissajous figure for the discharge power of $1.0 \mathrm{~W}$. The power of the discharges during the experimental research ranged of $P=1.0-2.2 \mathrm{~W}$, with the supply voltage of $V_{p}=7.5-15 \mathrm{kV}$. High voltage power supply with a frequency of $50 \mathrm{~Hz}$ was used to power the DBD plasma actuator.

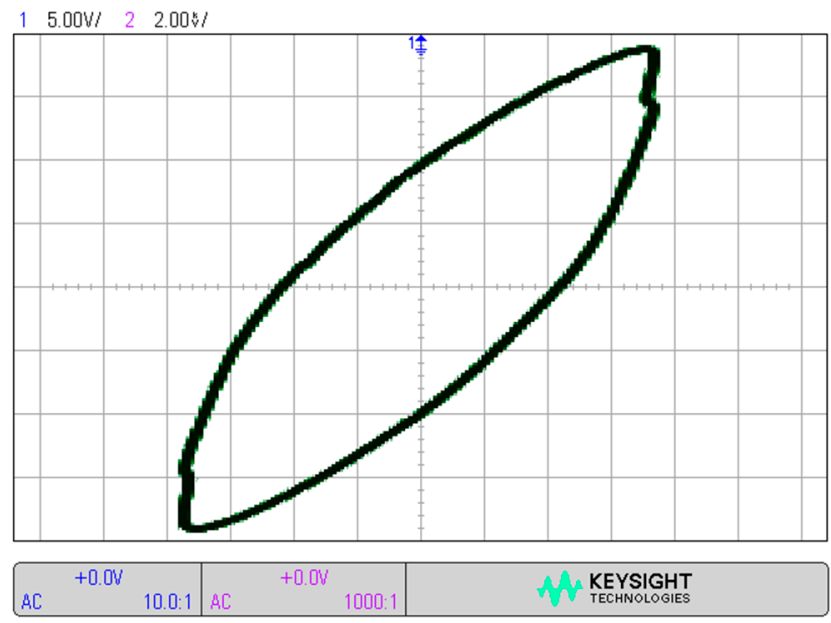

Figure 7. Lissajous figure for $P=1.0 \mathrm{~W}$ discharge power, at $V_{p}=7.5 \mathrm{kV}$ supply voltage.

During the tunnel tests, the forces acting on the wing model were also recorded, as shown in Table 1. 
Table 1. Normal and axial force measurements at angle of attack of $15^{\circ}$.

\begin{tabular}{ccccc}
\hline $\boldsymbol{V}(\mathbf{m} / \mathbf{s})$ & \multicolumn{2}{c}{ Normal Force (N) } & \multicolumn{2}{c}{ Axial Force (N) } \\
\hline & OFF & ON & OFF & ON \\
5 & 1.52 & 1.57 & 0.08 & 0.09 \\
10 & 6.46 & 6.46 & 0.31 & 0.31 \\
15 & 13.35 & 13.48 & 0.65 & 0.66 \\
\hline
\end{tabular}

The Table 1 compares the forces acting on the wing model under the same conditions with the plasma actuator turn on and turn off. The uncertainty of measurements, calculated on the basis of the results of experimental research, is presented in Table 2.

Table 2. The uncertainty measured of forces for angle of attack of $15^{\circ}$.

\begin{tabular}{|c|c|c|c|c|}
\hline & \multicolumn{4}{|c|}{ Measurement Uncertainty } \\
\hline & \multicolumn{2}{|c|}{ Normal Force (N) } & \multicolumn{2}{|c|}{ Axial Force (N) } \\
\hline & \multicolumn{4}{|c|}{ Plasma actuator } \\
\hline$V(\mathrm{~m} / \mathrm{s})$ & OFF & $\mathrm{ON}$ & OFF & ON \\
\hline 5 & 0.007 & 0.013 & 0.002 & 0.006 \\
\hline 10 & 0.003 & 0.007 & 0.002 & 0.006 \\
\hline 15 & 0.083 & 0.075 & 0.004 & 0.008 \\
\hline
\end{tabular}

In addition to the results presented in Table 1, the effectiveness of the plasma actuator is also confirmed by photos taken with a high-speed camera. The use of a smoke generator and high-speed camera allows to observe the air flow for the system with the plasma actuator turn on and turn off. The photos show the influence of the DBD system on the change of air flow over the upper surface of the wing. Turning on the plasma actuator allows for a more laminar airflow as shown in Figure 8b. During the experiment, the camera recorded photos at 3000 frames per second, which provided high quality photos.

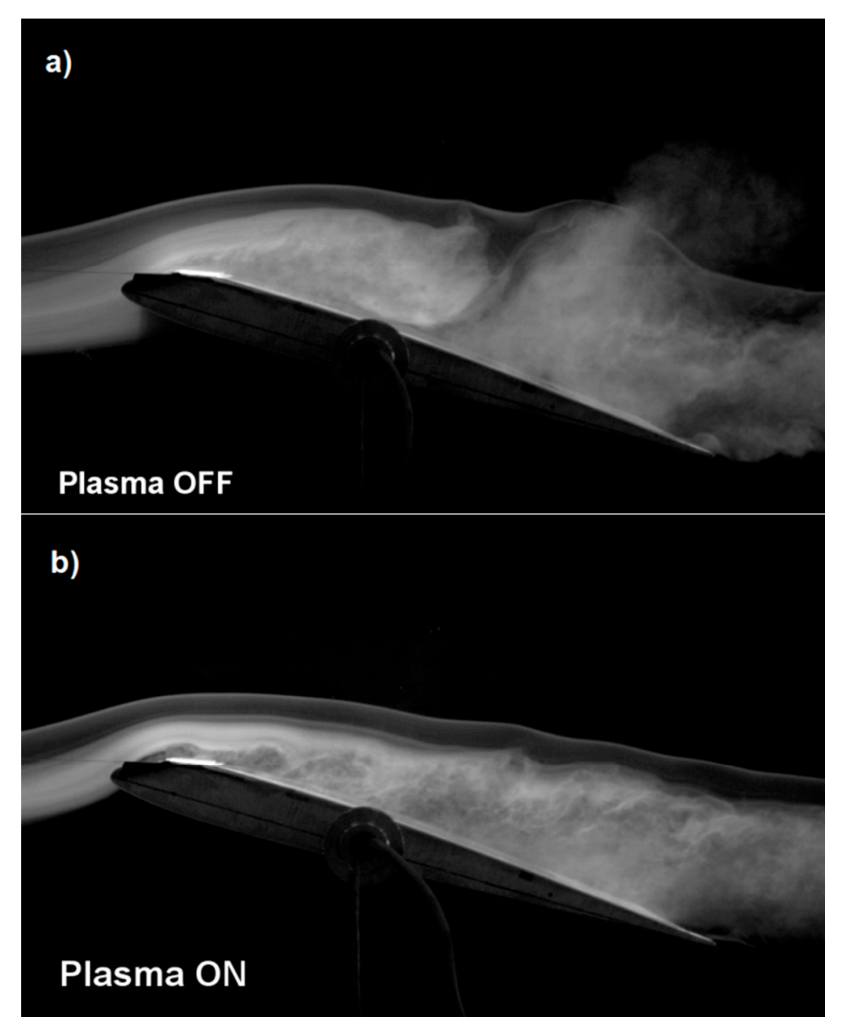

Figure 8. Tunnel photos of the wing model with the SD 7003 profile for the angle of attack $\alpha=15^{\circ}$ at the air flow velocity $V=5 \mathrm{~m} / \mathrm{s}$ for; (a) plasma actuator turned off and (b) plasma actuator turned on. 
The presented results of experimental tests in the wind tunnel on the SD 7003 wing model show the effectiveness of the DBD plasma actuator with two mesh electrodes, which is confirmed by the results presented in Table 1 and the tunnel photos in Figures 8-10. Experimental research were carried out for a high angle of attack for which the SD 7003 profile wing loses its lift under normal conditions (critical angle of attack about $11^{\circ}$ ).
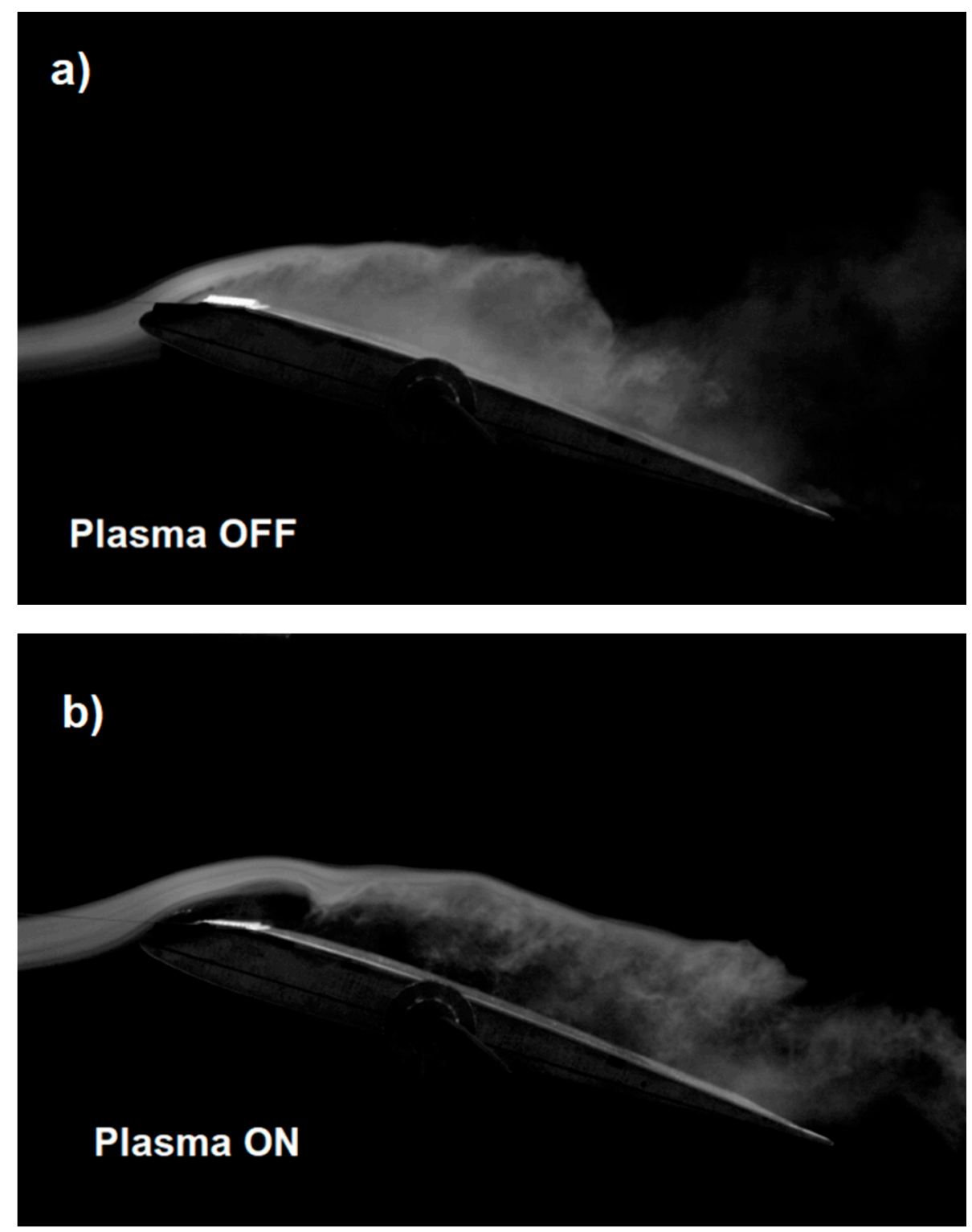

Figure 9. Tunnel photos of the wing model with the SD 7003 profile for the angle of attack $\alpha=15^{\circ}$ at the air flow velocity $V=10 \mathrm{~m} / \mathrm{s}$ for; (a) plasma actuator turned off and (b) plasma actuator turned on.

Figure 8 a shows the wing model with the plasma actuator turned off, with visible non-laminar airflow. The point of separation and turbulence are especially visible at the end of the wing near the trailing edge. Turning on the plasma actuator at the air velocity of $V=5 \mathrm{~m} / \mathrm{s}$ in Figure $8 \mathrm{~b}$ allowed to significantly reduce the turbulence that is visible in Figure $8 \mathrm{a}$. The airflow in Figure $8 \mathrm{~b}$ is not completely laminar but much less turbulent than the flow with the plasma actuator off Figure 8a. The tunnel photo shown in Figure 9a for an air velocity of $10 \mathrm{~m} / \mathrm{s}$ and Figure 10a for an air velocity of $15 \mathrm{~m} / \mathrm{s}$ for the configuration with plasma actuator turned off is non-laminar with visible turbulence, while in Figures $9 \mathrm{~b}$ and $10 \mathrm{~b}$ with plasma actuator turned on, the airflow is more laminar at air flow velocity of $V=10 \mathrm{~m} / \mathrm{s}$ and $V=15 \mathrm{~m} / \mathrm{s}$. Comparing Figures $8 \mathrm{~b}, 9 \mathrm{~b}$ and $10 \mathrm{~b}$ (Plasma On), we can see 
the negative effect of airflow velocity on the efficiency of the plasma actuator. In Figures $9 \mathrm{~b}$ and $10 \mathrm{~b}$ the air jets do not adhere to the wing, which results in a reduced increase in lift.
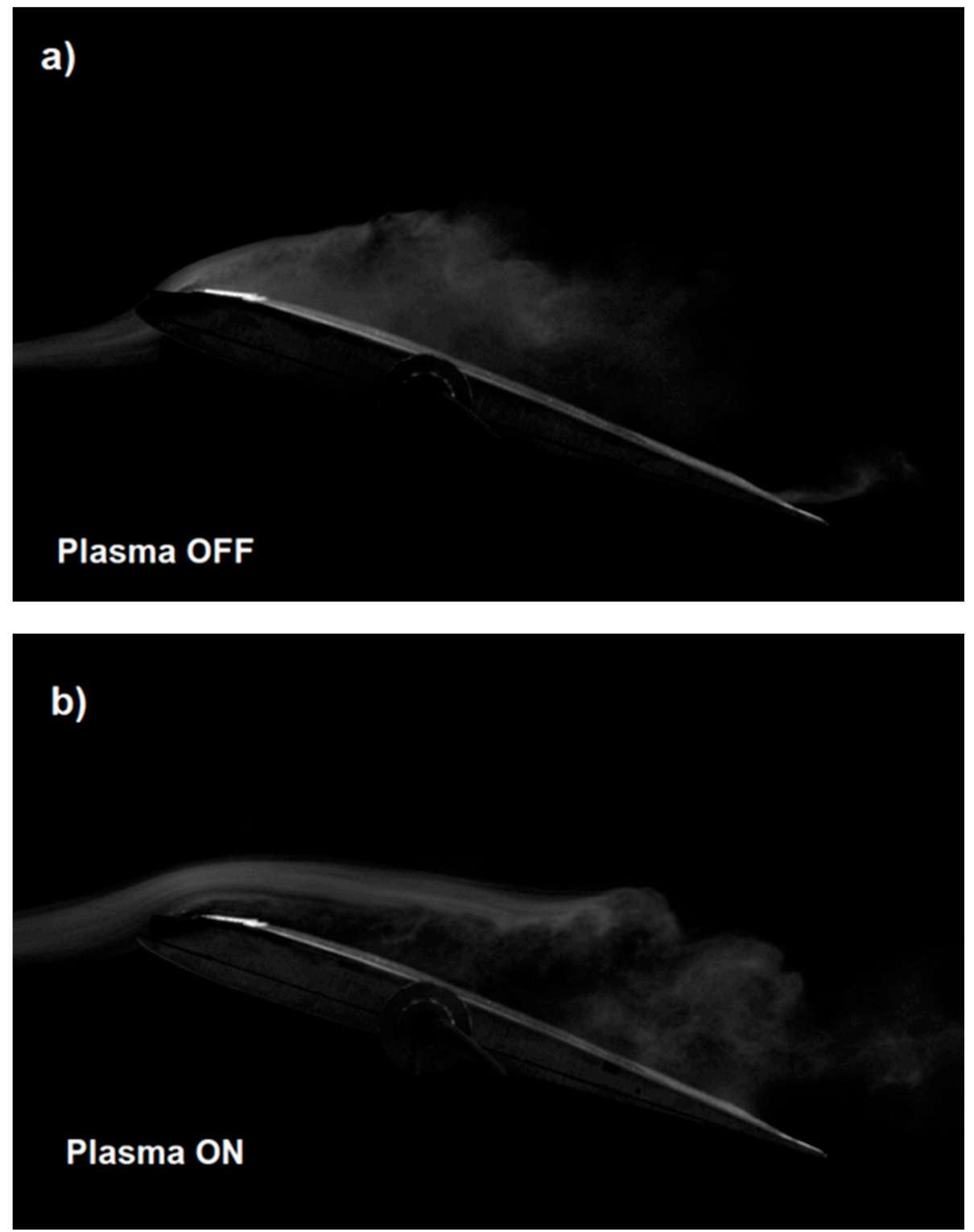

Figure 10. Tunnel photos of the wing model with the SD 7003 profile for the angle of attack $\alpha=15^{\circ}$ at the air flow velocity $V=15 \mathrm{~m} / \mathrm{s}$ for; (a) plasma actuator turned off and (b) plasma actuator turned on.

The lift coefficient $C_{L}$ was used to determine the lift force changes depending on the air flow velocity and the angle of attack. Figure 11 shows the change in the lift coefficient $\mathrm{C}_{\mathrm{L}}$ of the wing model with the plasma actuator turn off and turn on. The changes in the lift coefficient presented in Table 3 are most visible on the graph for the flow velocity in the range of $V=5-10 \mathrm{~m} / \mathrm{s}$, when the air flow velocity is low. 


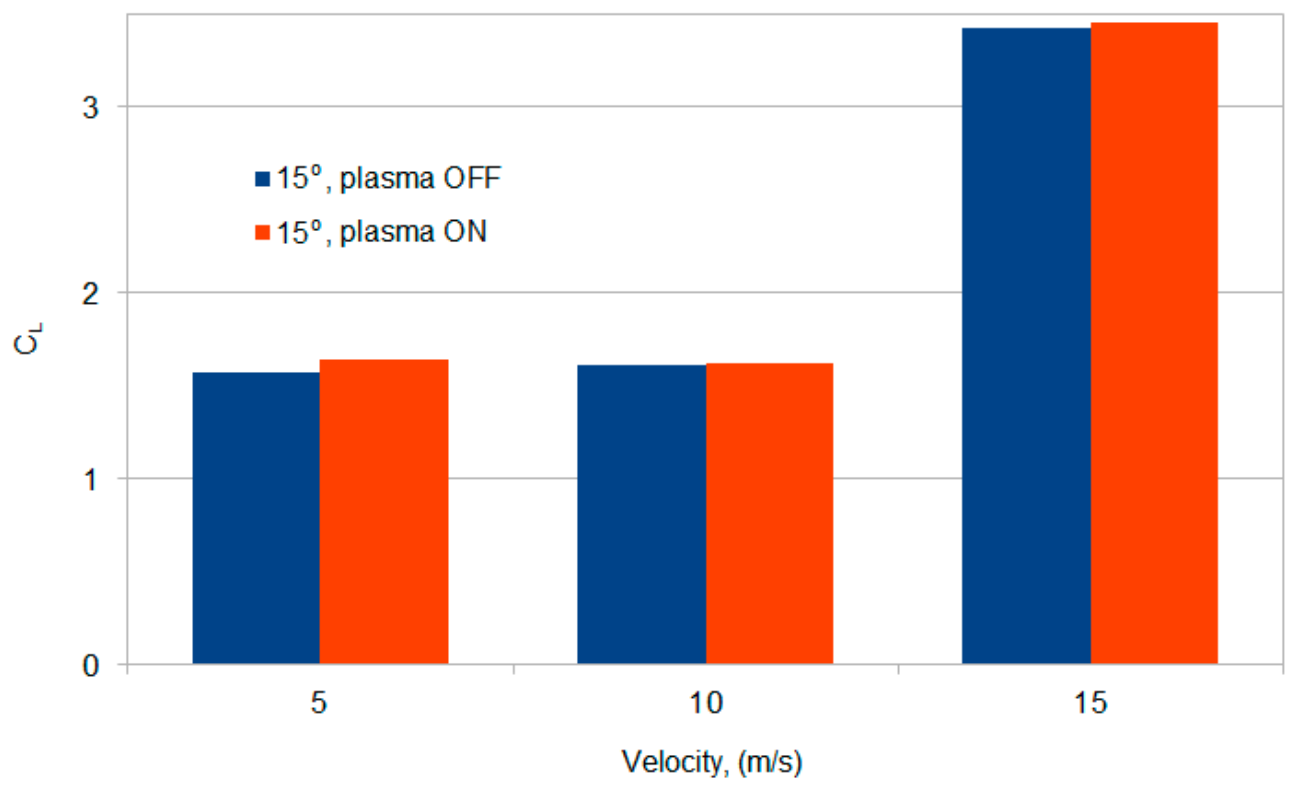

Figure 11. Graph of changes in the trend of the lift force coefficient for the wing model for the angle of attack $\alpha=15^{\circ}$ and the air flow speed in the range of $V=5-15 \mathrm{~m} / \mathrm{s}$, when the plasma actuator turn on and turn off.

Table 3. Change of the lift coefficient $C_{L}$ for the angle of attack of $15^{\circ}$.

\begin{tabular}{ccc}
\hline $\boldsymbol{V}(\mathbf{m} / \mathbf{s})$ & \multicolumn{2}{c}{ Lift Coefficient $\mathbf{C}_{\mathbf{L}}$} \\
\hline & Plasma actuator OFF & Plasma actuator ON \\
5 & 1.57 & 1.62 \\
10 & 1.61 & 1.62 \\
15 & 3.42 & 3.44 \\
\hline
\end{tabular}

Figure 12 and Table 4 presents changes in resultant force depending on air flow velocity in the range of 5 to $15 \mathrm{~m} / \mathrm{s}$ and angle of attack $15^{\circ}$.

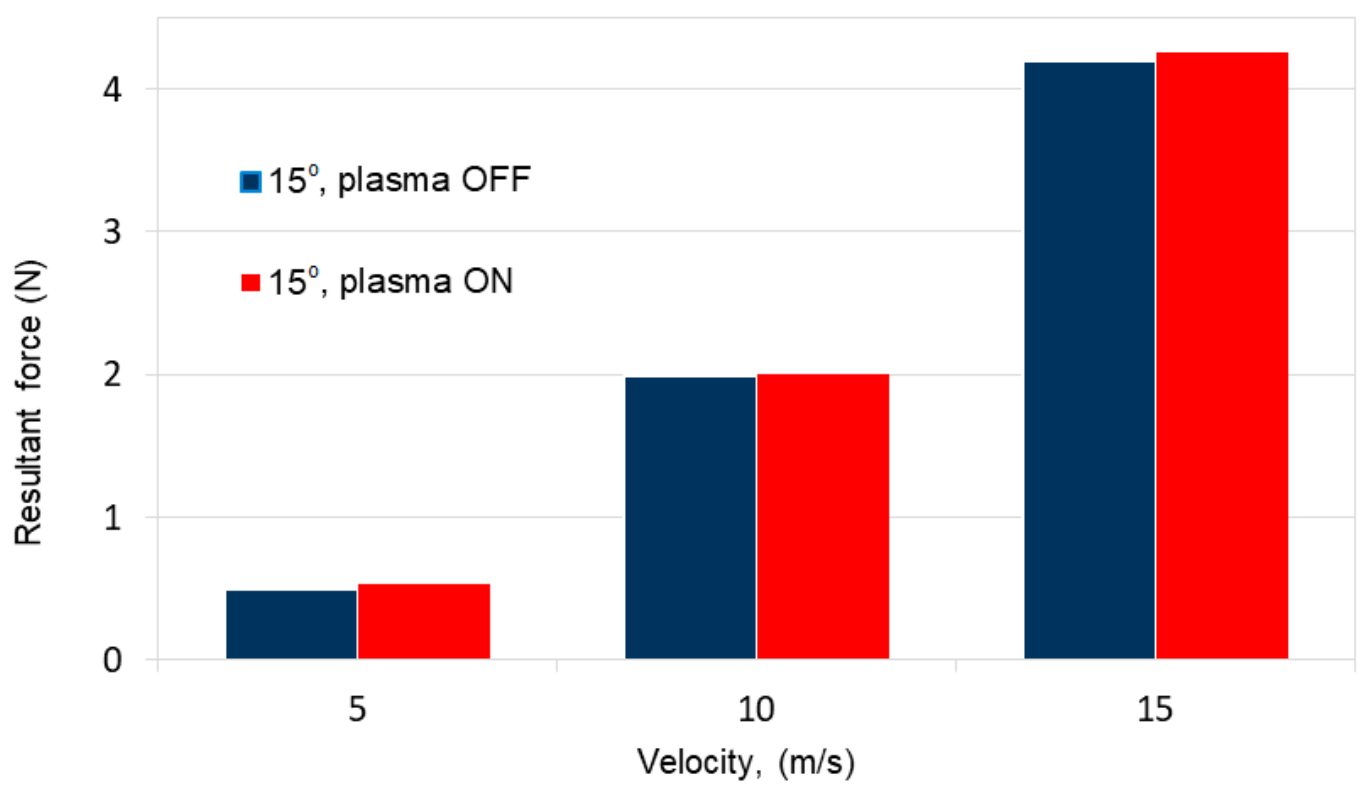

Figure 12. Changes in the resultant force trend depending on air flow velocity in the range of 5-15 m/s and angle of attack $15^{\circ}$. 
Table 4. Changes in resultant force depending on air flow velocity and angle of attack $15^{\circ}$.

\begin{tabular}{ccc}
\hline$V(\mathbf{m} / \mathbf{s})$ & \multicolumn{2}{c}{ Resultant Force $\mathbf{( N )}$} \\
\hline & Plasma actuator OFF & Plasma actuator ON \\
5 & 0.5 & 0.53 \\
10 & 1.98 & 2 \\
15 & 4.19 & 4.25 \\
\hline
\end{tabular}

The results of the experimental tests presented in Table 4 show the change of the resultant force trend for the air flow velocity in the range from $V=5 \mathrm{~m} / \mathrm{s}$ to $V=15 \mathrm{~m} / \mathrm{s}$ for the angle of attack of $15^{\circ}$.

The changes in the resultant force presented in the diagram in Figure 12 are small because the changes in the lift coefficient of the tested SD 7003 wing profile are small because the critical angle of attack for this profile is $11^{\circ}$. In the experimental tests, the experiment was carried out for an angle of $15^{\circ}$ greater than the critical angle of attack. At an angle of attack greater than $11^{\circ}$, the SD 7003 profile loses total lift and stall occurs.

The use of a plasma actuator allowed to obtain a positive increase in the lifting force as well as the resultant force even in such unfavorable conditions.

The main factor influencing the increase in the lift force and the efficiency of the plasma actuator with two mesh electrodes is the increase in the discharge area. The discharge on the high-voltage mesh electrode is created over the entire surface of the electrode, creating a wide discharge belt (in a classic plasma actuator with a solid electrode, the discharge is generated only on one edge). The design solution presented in the manuscript is a new solution for changing the geometry of the electrodes and is not used by other researchers.

The experimental studies show that the efficiency of the plasma actuator depends on several factors, including air flow velocity $V$, as well as the parameters of the plasma actuator supply system and the power of the discharges. Many experimental studies confirm that the efficiency of DBD systems decreases with the increase in gas flow velocity (e.g., ozone generators, the concentration of ozone decreases) [32-34], the same is the case with DBD plasma actuators $[35,36]$ because the operation of the plasma actuator is precisely to generate the plasma "ion wind".

\section{Conclusions}

The results of the conducted experimental research confirm the effectiveness of the new type of plasma actuator with two mesh electrodes. Tunnel tests of the wing model with the SD7003 profile allowed to obtain an increase in the lift coefficient by $5 \%$ at a high angle of attack of $15^{\circ}$ (critical angle of attack $11^{\circ}$ ), which is confirmed by Figure 11 and Table 3 . The high efficiency of the tested design of the plasma actuator is possible because the discharges appear at both edges and directly through the surface of the high voltage electrode. These phenomena do not occur in the classic solution with impermeable solid electrodes, in which the discharges are only on one edge, discharges directly through the surface of the HV solid electrode are impossible. The geometry of the electrodes is a key factor in the efficiency of the plasma actuator. Increasing the discharge area allows for a higher gas ionization density, affecting the increase in the lift coefficient $\mathrm{C}_{\mathrm{L}}$. Many researchers change the shape of the solid electrodes to increase the efficiency of the plasma actuator. The mesh electrode increases the effective surface of the discharges, thus increasing the efficiency of the plasma actuator with two mesh electrodes. Another important factor is the supply system, especially the supply voltage and frequency. Both of these factors directly affect the power of the discharges. The plasma actuator with two mesh electrodes described in the manuscript is a new design that requires further optimization.

The conducted experimental research and the obtained results show the potential of the new design of the plasma actuator. In order to determine the potential of the new design of the plasma actuator, it requires further experimental research to determine the optimal configuration of the system, one of the factors that should be examined is the determination of the mounting location and the number of HV electrodes. 
Author Contributions: Conceptualization, E.G.; formal analysis, J.M.; investigation, E.G., J.P. and J.J.; project administration, J.L.; writing-original draft, E.G. All authors have read and agreed to the published version of the manuscript.

Funding: This research received no external funding.

Institutional Review Board Statement: Not applicable.

Informed Consent Statement: Not applicable.

Data Availability Statement: Data is contained within the article.

Acknowledgments: We would like to offer our sincere thanks to the Institute of Technical Sciences and Aviation, The State School of Higher Education Chełm (Poland) for agreeing to conduct tests in the wind tunnel.

Conflicts of Interest: The authors declare no conflict of interest.

\section{References}

1. Xue, C.-J.; Han, Y.; Qi, W.-G.; Dai, J.-H. Landing-Gear Drop-Test Rig Development and Application for Light Airplanes. J. Aircr. 2012, 49, 2064-2076. [CrossRef]

2. Pytka, J.; Budzyński, P.; Łyszczyk, T.; Józwik, J.; Michałowska, J.; Tofil, A.; Błażejczak, D.; Laskowski, J. Determining Wheel Forces and Moments on Aircraft Landing Gear with a Dynamometer Sensor. Sensors 2019, 20, 227. [CrossRef] [PubMed]

3. Pytka, J.; Józwik, J.; Budzyński, P.; Łyszczyk, T.; Tofil, A.; Gnapowski, E.; Laskowski, J. Wheel Dynamometer System for Aircraft Landing Gear Testing. Measurement 2019, 148, 106918. [CrossRef]

4. Zhou, Y.; Yunxia, C.; Rui, K. A Study of Aircraft Landing Gear Testing System on PHM. In Proceedings of the Prognostics and System Health Managment Conference, Montreal, QC, Canada, 25-29 September 2011; pp. 1-4. [CrossRef]

5. Ninian, D.; Dakka, S.M. Design, Development and Testing of Shape Shifting Wing Model. Aerospace 2017, 4, 52. [CrossRef]

6. Gerard, I.J. Mechanical Tests of Aircraft Structural Components. J. R. Aeronaut. Soc. 1932, 36, 673-703. [CrossRef]

7. Gnapowski, E.; Pytka, J.; Jozwik, J.; Michalowska, J. Wind Tunnel Testing of Mesh Electrodes Plasma Actuator. In Proceedings of the 7th IEEE Workshop on Metrology for AeroSpace, Pisa, Italy, 22-24 June 2020; pp. 426-429.

8. Whalley, R.D.; Choi, K.S. The Starting Vortex in Quiescent Air Induced by Dielectric-Barrier-Discharge Plasma. J. Fluid Mech. 2012, 703, 192-203. [CrossRef]

9. Robinson, M. A History of the Electric Wind. Am. J. Phys. 1962, 30, 366-372. [CrossRef]

10. Messanelli, F.; Belan, M. Ionic Wind Measurements on Multi-Tip Plasma Actuators. EPJ Web Conf. 2016, 114, 2073. [CrossRef]

11. Séraudie, A.; Aubert, E.; Naudé, N.; Cambronne, J. Effect of Plasma Actuators on a Flat Plate Laminar Boundary Layer in Subsonic Conditions. In Proceedings of the 3rd AIAA Flow Control Conference, San Francisco, CA, USA, 5-8 June 2006.

12. Wang, C.-C.; Durscher, R.; Roy, S. Three-Dimensional Effects of Curved Plasma Actuators in Quiescent Air. J. Appl. Phys. 2011, 109, 083305. [CrossRef]

13. Roy, S.; Wang, C.C. Bulk Flow Modification with Horseshoe and Serpentine Plasma Actuators. J. Phys. D Appl. Phys. 2009, 42. [CrossRef]

14. Berendt, A.; Podliński, J.; Mizeraczyk, J. Multi DBD Plasma Actuator for Flow Separation Control around NACA0012 and NACA0015 Airfoil Models. Przeglad Elektrotechniczny 2012, 88, 18-21.

15. Leroy, P.; Audier, J.; Podlinski, A.; Berendt, D.H.; Mizeraczyk, J. Enhancement of Lift and Drag Performances of NACA0012 Airfoil by Multi-DBD Plasma Actuator with Additional Floating Interelectrodes. In Proceedings of the International Symposium on Electrohydrodynamics, Gdańsk, Poland, 23-26 September 2012.

16. Gnapowski, E. Effect of Mesh Electrodes Geometry on the Ozone Concentration in the Presence of Micanite Dielectric. Adv. Sci. Technol. Res. J. 2018, 12, 76-80. [CrossRef]

17. Kogelschatz, U.; Eliasson, B.; Egli, W. From Ozone Generators to at Television Screens: History and Future Potential of DielectricBarrier Discharges. Pure Appl. Chem. 1999, 71, 1819-1828. [CrossRef]

18. Han, M.; Li, J.; Niu, Z.; Liang, H.; Zhao, G.; Hua, W.; Menghu, H.; Jun, L.; Zhongguo, N.; Hua, L.; et al. Aerodynamic performance enhancement of a flying wing using nanosecond pulsed DBD plasma actuator. Chin. J. Aeronaut. 2015, 28, 377-384. [CrossRef]

19. Gnapowski, E.; Gnapowski, S.; Pytka, J. Effect of Mesh Geometry on Power, Efficiency, and Homogeneity of Barrier Discharges in the Presence of Glass Dielectric. IEEE Trans. Plasma Sci. 2018, 46, 3493-3498. [CrossRef]

20. Deng, X.T.; Kong, M.G. Frequency Range of Stable Dielectric-Barrier Discharges in Atmospheric He and N². IEEE Trans. Plasma Sci. 2004, 32, 1709-1715. [CrossRef]

21. Gnapowski, E.; Gnapowski, S. Changes in the Power Discharge in a Plasma Reactor Using Porous Versus Solid Dielectric Barriers and Meshes Electrodes. IEEE Trans. Plasma Sci. 2016, 44, 1-5. [CrossRef]

22. Kim, J.; Kim, S.-J.; Lee, Y.-N.; Kim, I.T.; Cho, G. Discharge Characteristics and Plasma Erosion of Various Dielectric Materials in the Dielectric Barrier Discharges. Appl. Sci. 2018, 8, 1294. [CrossRef] 
23. Asada, K.; Ninomiya, Y.; Fujii, K.; Oyama, A. Airfoil Flow Experiment on the Duty Cycle of DBD Plasma Actuator. In Proceedings of the 47th AIAA Aerospace Sciences Meeting including The New Horizons Forum and Aerospace Exposition, Orlando, FL, USA, 5-8 January 2009.

24. Zhao, G.; Li, Y.; Liang, H.; Han, M.; Wu, Y. Flow Separation Control on Swept Wing with Nanosecond Pulse Driven DBD Plasma Actuators. Chin. J. Aeronaut. 2015, 28, 368-376. [CrossRef]

25. Patel, M.P.; Ng, T.T.; Vasudevan, S.; Corke, T.C.; Post, M.L.; McLaughlin, T.E.; Suchomel, C.F. Scaling Effects of an Aerodynamic Plasma Actuator. J. Aircr. 2008, 45, 223-236. [CrossRef]

26. Qi, X.-H.; Yang, L.; Yan, H.-J.; Jin, Y.; Ren, C.-S. Plasma Actuator Performance Driven by Dual-Power Supply Voltage-AC High Voltage Superimposed with Pulse Bias Voltage. IEEE Trans. Plasma Sci. 2017, 45, 412-422. [CrossRef]

27. Dong, D.; Hong, J.; Pouvesle, V.; Boucinha, W.R.; Leroy, A. Study of a DBD Plasma Actuator Dedicated to Airflow Separation Control. In Proceedings of the IEEE 35th International Conference on Plasma Science, Karlsruhe, Germany, 15-19 June 2008 ; p. 1.

28. Huang, J.; Corke, T.C.; Thomas, F.O. Plasma Actuators for Separation Control of Low-Pressure Turbine Blades. AIAA J. 2012, 44, 51-57.

29. Nishida, H.; Shiraishi, T. Experimental Characterization of Dual-Grounded Tri-Electrode Plasma Actuator. AIAA J. 2015, 53, 3157-3166. [CrossRef]

30. Gnapowski, E.; Gnapowski, S.; Pytka, J. The Impact of Dielectrics on the Electrical Capacity, Concentration, Efficiency Ozone Generation for the Plasma Reactor with Mesh Electrodes. Plasma Sci. Technol. 2018, 20, 085505. [CrossRef]

31. Jiang, L.; Li, Q.; Zhu, D.; Attoui, M.; Deng, Z.; Tang, J.; Jiang, J. Comparison of Nanoparticle Generation by Two Plasma Techniques: Dielectric Barrier Discharge and Spark Discharge. Aerosol Sci. Technol. 2017, 51, 206-213. [CrossRef]

32. Cuong, L.C.; Nghi, N.H.; Dieu, T.V.; Oanh, D.T.Y.; Vuong, D.D. Influence of Oxygen Concentration, Feed Gas Flow Rate and Air Humidity on the Output of Ozone Produced by Corona Discharge. Vietnam. J. Chem. 2019, 57, 604-608. [CrossRef]

33. Vaduganathan, L.; Poonamallie, B.A.; Nagalingam, M. Effects of Temperature and Flow Rates of Ozone Generator on the DBD by Varying Various Electrical Parameters. Am. J. Appl. Sci. 2012, 9, 1496-1502. [CrossRef]

34. Prasetyaningrum, A.; Kusumaningtyas, D.A.; Suseno, P.; Ratnawati, R. Effect of pH and Gas Flow Rate on Ozone Mass Transfer of K-Carrageenan Solution in Bubble Column Reactor. Reakt. Chem. Eng. J. 2018, 18, 177-182. [CrossRef]

35. Shimizu, K.; Mizuno, Y.; Blajan, M. Basic Study on Flow Control by Using Plasma Actuator. IEEE Ind. Appl. Soc. Annu. Meet. 2013, 51, 1-6. [CrossRef]

36. Vorobiev, A.; Rennie, R.M.; Jumper, E.J. Lift Enhancement by Plasma Actuators at Low Reynolds Numbers. J. Aircr. 2013, 50, 12-19. [CrossRef] 